\title{
Evaluation of epidemiological lectures using peer instruction: case-study focusing on the importance of ConcepTests
}

\author{
Toshiharu Mitsuhashi ${ }^{\text {Corresp. } 1}$ \\ ${ }^{1}$ Center for Innovative Clinical Medicine, Okayama University Hospital, Okayama, Japan \\ Corresponding Author: Toshiharu Mitsuhashi \\ Email address: mitsuh-t@cc.okayama-u.ac.jp
}

Background. In clinical research, the ability to properly analyze data is a necessary skill that cannot be learned simply by listening to lectures. Interactive classes, such as Peer Instruction (PI), are required to help medical students understand the concept of epidemiology for future valid research. In PI lectures, ConcepTests are conducted to confirm and deepen students' understanding of the lecture material. Although it is important to evaluate PI lectures, there have been no studies conducted on PI lectures in epidemiology. This study employed the ConcepTest to evaluate PI lectures in a medical school epidemiology class to measure the efficiency of active learning techniques and the usefulness of ConcepTests in determining effective active learning approaches.

Methods. The PI lecture was conducted as part of an existing epidemiology class for fourth-year medical students at Okayama University on October 17, 2019. The lecture was conducted as follows. The lecturer taught the fundamental concepts of epidemiology and presented the ConcepTest to students. After answering the test, students were provided with the answer distribution, followed by peer discussion. After the discussion, students answered the ConcepTest again, and a new answer distribution was presented. Subsequently, the lecturer announced the correct answers and delivered a commentary. The ConcepTest comprised five questions, each related to fundamental concepts of epidemiology. Students' responses to five ConcepTests were collected and analyzed by calculating the proportion of correct answers before and after the discussion, as well as PI efficiency to evaluate the PI lecture.

Results. Overall, 121 students attended the epidemiology lecture. The proportion of correct answers before the discussion ranged from 0.217 to 0.458 , and after the peer discussion they ranged from 0.178 to 0.767 . The PI efficiency ranged from -0.051 to 0.657 , and was higher than the theoretical value in three ConcepTests. The efficiency was about the same as the theoretical value in one ConcepTest, and lower than the theoretical value in another.

Conclusion. In this study, the efficiency of a PI lecture was determined by calculating the PI efficiency of each ConcepTest. The results showed that the educational efficiency of a ConcepTest in epidemiology lectures can be widely distributed, ranging from efficient to inefficient. Particularly in three ConcepTests, the proportion of correct answers after the discussion and the PI efficiency were higher than the theoretical value. This suggests that PI lectures can be useful in epidemiology education with the efficient use of ConcepTests. 
1 Evaluation of Epidemiological Lectures Using Peer

2 Instruction: Case-study Focusing on the Importance

3 of ConcepTests

4

5 Toshiharu Mitsuhashi ${ }^{1}$

$6{ }^{1}$ Center for Innovative Clinical Medicine, Okayama University Hospital, Okayama, Japan

8 Corresponding Author:

9 Toshiharu Mitsuhashi ${ }^{1}$

10 2-5-1 Shikata-cho Kita-ku, Okayama, Okayama Prefecture, 700-8558, Japan

11 Email address: mitsuh-t@,cc.okayama-u.ac.jp

12 


\section{Abstract}

14 Background. In clinical research, the ability to properly analyze data is a necessary skill that cannot be learned simply by listening to lectures. Interactive classes, such as Peer Instruction (PI), are required to help medical students understand the concept of epidemiology for future valid research. In PI lectures, ConcepTests are conducted to confirm and deepen students' understanding of the lecture material. Although it is important to evaluate PI lectures, there have been no studies conducted on PI lectures in epidemiology. This study employed the ConcepTest to evaluate PI lectures in a medical school epidemiology class to measure the efficiency of active learning techniques and the usefulness of ConcepTests in determining effective active learning approaches.

Methods. The PI lecture was conducted as part of an existing epidemiology class for fourth-year medical students at Okayama University on October 17,2019. The lecture was conducted as follows. The lecturer taught the fundamental concepts of epidemiology and presented the ConcepTest to students. After answering the test, students were provided with the answer distribution, followed by peer discussion. After the discussion, students answered the ConcepTest again, and a new answer distribution was presented. Subsequently, the lecturer announced the correct answers and delivered a commentary. The ConcepTest comprised five questions, each related to fundamental concepts of epidemiology. Students' responses to five ConcepTests were collected and analyzed by calculating the proportion of correct answers before and after the discussion, as well as PI efficiency to evaluate the PI lecture.

Results. Overall, 121 students attended the epidemiology lecture. The proportion of correct answers before the discussion ranged from 0.217 to 0.458 , and after the peer discussion they ranged from 0.178 to 0.767 . The PI efficiency ranged from -0.051 to 0.657 , and was higher than the theoretical value in three ConcepTests. The efficiency was about the same as the theoretical 
37 value in one ConcepTest, and lower than the theoretical value in another.

38 Conclusion. In this study, the efficiency of a PI lecture was determined by calculating the PI efficiency of each ConcepTest. The results showed that the educational efficiency of a ConcepTest in epidemiology lectures can be widely distributed, ranging from efficient to inefficient. Particularly in three ConcepTests, the proportion of correct answers after the discussion and the PI efficiency were higher than the theoretical value. This suggests that PI lectures can be useful in epidemiology education with the efficient use of ConcepTests.

\section{Introduction}

Recently, there has been growing interest in data science education within academic programs (Huppenkothen et al., 2018; Guzman et al., 2019; Park et al., 2019). In medical research in particular, clinical data-based research is becoming increasingly important (Macleod et al., 2014; Sandercock \& Whiteley, 2018; Fridsma, 2018). To learn how to appropriately analyze clinical data and conduct clinical research, medical students must take data science undergraduate classes (e.g., epidemiology). In other words, high-quality epidemiology education is required for highquality clinical research.

It has been shown that data science cannot be learned efficiently through lectures alone (Haller $\&$ Krauss, 2002). Therefore, Peer Instruction (PI) has recently attracted the attention of educational practitioners (Hilborn, 1997). PI is a type of interactive learning that is easy to incorporate into conventional lecture styles and can be conducted even with a large number of students (Crouch, 1998), unlike small-group interactive methods such as problem-based learning. PI education has been introduced in various fields, and PI lectures have been conducted primarily in the fields of physics, mathematics, and engineering (Pilzer, 2001; Crouch \& Mazur, 2001; Schmidt, 2011). The effects of PI lectures on students' conceptual understanding in these 
61 fields were shown to improve students' understanding and satisfaction (Giuliodori, Lujan \&

62 DiCarlo, 2006; Relling \& Giuliodori, 2015; University College London, 2018; Vázquez-García,

2018). Although educational methods that enable better understanding of epidemiology concepts have been studied (Goldmann et al., 2018; Dankner et al., 2018; Sohn et al., 2019), limited research has been conducted on PI lectures in epidemiology (Katyal et al., 2016). Considering its effective application in other fields, PI may be a promising educational method in epidemiology.

$$
\text { During PI lectures, important concepts that students should learn are tested using the }
$$
ConcepTest, through which a lecturer can confirm students' understanding, and students can, in turn, deepen their understanding. The effectiveness of the ConcepTest is one of the important factors determining its success or failure (Crouch \& Mazur, 2001; Nitta, 2010). Additionally, students' responses to the ConcepTests provide further insights into student learning. However, there have been no reports of ConcepTest evaluations for PI in epidemiology. That is, it is not clear whether the learning efficiency per ConcepTest in epidemiology is high or low. This knowledge gap needs to be filled. Therefore, this study aims to report the effectiveness of ConcepTests used in PI lectures in epidemiology.

\section{Materials \& Methods}

\section{Ethical consent}

The study was approved by the Okayama University Graduate School of Medicine, Dentistry and Pharmaceutical Sciences, and Okayama University Hospital Ethics Committee (approval number K1909-037). The purpose and methods of the study were adequately presented to the students on paper, informed consent was obtained, and the students were told that they were free to withdraw participation for any reason.

\section{Study design and settings}


The PI lecture in this study was presented on October 17, 2019 to an existing epidemiology class for fourth-year medical students at Okayama University. As PI lectures had not been previously presented at the Okayama University School of Medicine, the PI lecture style was explained to the students. Students' answers to five ConcepTests conducted during the PI lecture were collected. The author designed and oversaw all exercises and ConcepTests.

\section{Lecture contents}

Students were not informed in advance that they would be presenting PI lectures, nor were they instructed to make special preparations for the PI lectures. The PI lecture was conducted as part of an epidemiology and statistics exercise. The lecture time was 80 minutes, and it was divided into a series of five short sections that dealt with the following topics:

1. Epidemiological indicators (risk, incidence, and prevalence)

2. Descriptive epidemiology (spot map and epidemic curve)

3. Cohort and case-control study (study concept and interpretation of a two-by-two table)

4. Random error (error evaluation and interpretation of confidence interval)

5. Systematic error (selection, information, and confounding biases)

After the PI lecture, statistical analysis was performed using the statistical software Epi Info 7 (www.cdc.gov/epiinfo/index.html).

\section{Mentimeter as a PI tool}

$$
\text { In this study, Mentimeter (www.mentimeter.com), a web-based interactive presentation }
$$
software often used in interactive education, was used as a PI tool (Andriani, Dewi \& Sagala, 2019; Moorhouse \& Kohnke, 2020). Via the Internet, students can answer questions incorporated into the presentation and their answers are tabulated immediately. The lecturer can present the compiled results to the student at an appropriate time. Using the Mentimeter, the author practiced several times before the PI lecture to ensure that the students' responses were captured for the 
ConcepTest.

\section{ConcepTest in the PI lecture}

After explaining each of the five themes, a ConcepTest was conducted to confirm students' understanding of the lecture material. The contents of the ConcepTests are shown in the Appendix table. ConcepTest \#1 presented a question about whether the risk or prevalence could be calculated from the information provided. The epidemic curve presented in ConcepTest \#2 concerned a food poisoning incident that occurred on an aircraft in 1984 and was quoted from the literature (Tauxe et al., 1987). This test asked students to interpret the epidemic curve.

ConcepTest \#3 consisted of a two-by-two table about thalidomide teratogenicity and was quoted from a Japanese book titled Shimin no tameno ekigaku nyūmon (Introduction to Epidemiology for Citizens) (Tsuda, 2003). This test asked students to interpret the two-by-two table for a casecontrol study. ConcepTest \# 4 provided point estimates and confidence intervals for risk ratios, which students were asked to interpret. ConcepTest \# 5 asked about research methods that are less likely to have selection and/or information bias. ConcepTests \#1, \#4, and \#5 were generated from hypothetical scenarios. The topic of each ConcepTest corresponds to each of the five topics of the preceding lecture.

\section{PI method overview}

One set of the PI was performed in about 6 minutes as follows:

I. The lecturer presents the ConcepTest after the presentation.

II. Students answer via Mentimeter.

III. The lecturer presents the answer distribution.

IV. Students subsequently hold a discussion to convince each other of the correctness of their answers.

V. Students answer via Mentimeter again. 
133 VI. The lecturer presents the new answer distribution.

134 VII. The lecturer announces the correct answer and gives a commentary.

135 During Step IV, students were instructed to discuss their answers with other students seated

136 nearby. It can be assumed that students seated nearby would have an easy relationship with each

137 other, so this method was adopted. Therefore, in some cases, students with the same opinions

138 held a discussion with each other, while in other cases, students with opposite opinions

139 conducted a discussion.

140 Statistical analysis

141 Simple tabulations were performed using Excel 2019 (Microsoft Corporation, version 1911,

142 Redmond, WA, USA), and graph drawings were created using Stata software (Stata Corporation, 143 version 16.1, College Station, TX, USA).

144

\section{Student attributes}

The number and gender of respondents for each ConcepTest were tabulated.

\section{PI efficiency}

The effectiveness of the ConcepTest was measured using PI efficiency $\eta$, defined with the help of Hake's standardized gain (Kaneta \& Nitta, 2009; Nitta, 2010), as follows:

$$
\eta=\frac{N_{a}-N_{b}}{1-N_{b}}
$$

where the proportion of correct answers before and after the discussion is denoted by $N_{b}$ and $N_{a}$, respectively. It is considered that $\eta$ reflects the ease of understanding gained through PI.

\section{Theoretical value of PI efficiency and proportion of correct answers after the} discussion

The theoretical value of $N_{a}$ and $\eta$ can be expressed as a function of $N_{b}$, with some assumptions (Nitta, 2010), as follows: 
156

157

158

159

160

161

162

163

164

165

166

167

168

169

170

171

172

173

174

175

176

177

178

179

$$
\begin{gathered}
N_{a}=2 N_{b}-N_{b}^{2} \\
\eta=N_{b}
\end{gathered}
$$

The theoretical value was calculated according to these formulas, and the difference from the measured value is shown in Figures 1 and 2.

\section{Results}

\section{Descriptive statistics}

Table 1 provides an overview of the 121 students ( 34 women and 87 men) who enrolled for and attended the PI lecture. The numbers of respondents for each ConcepTest (before/after discussion) were 120/101 for \#1, 115/107 for \#2, 116/120 for \#3, 107/101 for \#4, and 110/106 for \#5.

\section{PI efficiency}

Table 2 provides $N_{b}, N_{a}$, the theoretical value of $N_{a}, \eta$, the theoretical value of $\eta$, and the gap between measured $\eta$ and theoretical value of $\eta . N_{b}$ ranged from 0.217 to 0.458 , and $N_{a}$ ranged from 0.178 to 0.767 . Except in ConcepTest \#2, $N_{a}$ was higher than $N_{b}$, and $\eta$ ranged from -0.051 to 0.657 . In ConcepTest \#2, $\eta$ was negative because the $N_{a}$ of 0.178 was less than the $N_{b}$ of 0.217. In this study, the average difference between the measured and theoretical values was 0.091, with a standard deviation of 0.216. A previous study on a physics PI lecture (Nitta, Matsuura \& Kudo, 2014) revealed an average difference of 0.062 and a standard deviation of 0.219. Therefore, although the average difference in the present study is slightly higher, the overall results are similar. It was not possible in this study to examine gender differences in the answers, because gender data and ConcepTest answers were recorded separately on the student roster and Mentimeter, respectively, and were thus impossible to correlate.

To more intuitively grasp the relationship between the theoretical and measured values, 
180 Figure 1 plots $N_{b}$ and $N_{a}$, and Figure 2 plots $N_{b}$ and $\eta$. The solid lines in each figure represent the theoretical value, and the dotted line in Figure 1 is a diagonal line, which indicates that the percentage of correct answers did not change after the discussion. In ConcepTest \#1, the theoretical and measured values were almost the same; in ConcepTests \#3 to \#5, the measured value was higher than the theoretical value. On the other hand, in ConcepTest \#2, the measured value was lower than the theoretical value, with a gap of -0.268 between the two. According to a previous study (Nitta, Matsuura \& Kudo, 2014), a gap of lower than -0.2 was reported in about $14.3 \%$ of ConcepTests; therefore, the low gap in this study is not unusual.

\section{Discussion}

This study aimed to employ the ConcepTest to evaluate PI in a medical school epidemiology class. The goal was to measure the efficiency of active learning techniques and examine the usefulness of ConcepTests in determining effective active learning approaches. As education methods become increasingly student-centered, researchers and educators need to employ empirical research methods, such as well-defined measures, to determine their efficacy.

$$
\text { In this study, PI efficiencies varied widely, probably because efficiency depends on the field }
$$
of study. For example, a mechanics lecture using a ConcepTest about position, velocity, and acceleration has high PI efficiency, whereas a ConcepTest on action and reaction has low PI efficiency (Kaneta \& Nitta, 2009; Takahashi \& Nitta, 2009; Nitta, Matsuura \& Kudo, 2014). In epidemiology, the ConcepTest about the case-control study showed high PI efficiency $(\eta=$ 0.657), but the ConcepTest about epidemic curves showed low PI efficiency $(\eta=-0.051)$.

One of the factors that indicates the success of PI lectures is high PI efficiency (Nitta, 2010; Nitta, Matsuura \& Kudo, 2014). Thus, a high learning effect might be obtained by presenting PI lectures in a field where the PI efficiency is high and conventional lectures in a field where the PI 
204

205

206

207

208

209

210

211

212

213

214

215

216

217

218

219

220

221

222

223

224

225

226

227

efficiency is low.

The proportion of correct answers before the discussion in this study ranged from 0.217 to 0.458, whereas the ideal range is said to be from 0.35 to 0.70 (Crouch \& Mazur, 2001). In this lecture, the proportion of correct answers before the discussion was less than 0.35 in three ConcepTests. Thus, few students might have had a fruitful discussion. This effect was particularly large in ConcepTest \#2 (0.217 proportion of correct answers before discussion), and the proportion of correct answers after the discussion was lower than that before the discussion. However, in other ConcepTests, the proportion of correct answers after the discussion was higher than the theoretical value even if the proportion of correct answers before the discussion was low. This suggests that student discussions may have a useful effect in learning epidemiology. Also, by using pre-learning activities, such as flipped classrooms, it may be possible to further increase PI efficiency (Rowley \& Green, 2015; Zheng \& Zhang, 2020; Sabale \& Chowdary, 2020).

There are three reasons that low PI efficiency was demonstrated only in ConcepTest \#2, which covered the epidemic curve. First, the lecture time may have been short. In the other ConcepTests, only the concepts covered in the ConcepTest were explained before the test; however, in ConcepTest \#2, an overall explanation of descriptive epidemiology was presented. As a result, little time was dedicated to explaining the epidemic curve. Second, the problem of false stereotypes may also have played a role. In ConcepTest \#2, students were asked a question about the epidemic curve of food poisoning. Students may have believed the stereotype that food poisoning is caused mainly by bacteria. For food poisoning, it is necessary to carefully consider all causes when assessing the situation. However, many students may have considered only bacterial food poisoning, which may have resulted in the low PI efficiency. ConcepTest \#2 was conducted with the pedagogical consideration that students should learn that it is necessary to 
228 think on the basis of epidemiological knowledge even for matters that are easily misunderstood, 229 but it seemed to have a negative impact on PI efficiency. Third, the different phrasing of the 230 questions in ConcepTest \#2 may have affected the students' responses. The questions for the 231 other four ConcepTests were phrased as "choose the most appropriate option." However, in 232 ConcepTest \#2, the question was phrased as "choose the least appropriate option." This may 233 have caused confusion for students and affected PI efficiency.

234 This study has several limitations. First, since only one lecture and five ConcepTests were utilized in this study, it is difficult to generalize the results. The PI efficiency might depend on not only the difficulty of the ConcepTests but also factors such as the interactions among

237 students (Figueiredo \& Figueiredo, 2020), students' background knowledge (Lasry, Mazur \& Watkins, 2008), and learning history (Nitta, Matsuura \& Kudo, 2014), among others. These factors may have had a strong effect on PI efficiency. Therefore, based solely on the results of this study, it cannot be concluded that PI efficiency is low for ConcepTests regarding the epidemic curve and high for ConcepTests regarding the case-control study. Second, the evaluation was conducted only for each ConcepTest, not for the PI lecture as a whole. In physics, objective tests such as the Force Concept Inventory are used to evaluate entire PI lectures (Hestenes, Wells \& Swackhamer, 1992). Further, there is a need for a subjective test for epidemiology. Third, the quality of the lectures may not be uniform. All lectures were conducted by the author, who provided explanations for all topics. Nonetheless, variations in quality can occur for each topic, and it should be noted that PI efficiency evaluates not only the ConcepTest, but a combination of the ConcepTest and pre-test lecture. Fourth, student discussions for each topic may not have been identical. While the discussion procedure was the same for all ConcepTests, students may not have been accustomed to engaging in discussions during class. Particularly at the beginning of the PI lecture, the effects of unfamiliarity with this format were 
252 considered significant. Therefore, in ConcepTests \#1 and \#2, the efficiency may have been lower 253 than in the ConcepTests that followed. Furthermore, students in Asia, including Japan, were 254 reported as not being active enough in active learning lectures (Shimizu et al, 2019). To avoid 255 these situations, it was necessary to promote a smooth discussion by conducting an icebreaker 256 before the PI lecture (Martin \& Bolliger, 2018; Basioudis, 2019), or by incorporating e-learning 257 into the lecture (Shimizu et al, 2019).

\section{Conclusions}

This study reported the effectiveness of ConcepTests used in a PI lecture in epidemiology. Based on the results of five ConcepTests, this study showed that PI efficiency can be widely used in epidemiology lectures. This is one of the few studies that has tested PI efficiency in epidemiological education. Further, the differences in PI efficiencies between study topics were noteworthy. In some ConcepTests, even if the proportion of correct answers before the discussion was low, the proportion after the discussion was higher than the theoretical value. epidemiology, it is necessary to develop objective standard tests. This suggests that PI lectures might be useful in epidemiology education.

However, the study had some limitations - mainly, a small number of ConcepTests and the difficulty of ensuring uniform quality across the PI lectures and discussions. Future research should address these issues, further utilizing ConcepTests in PI lectures and continually measuring PI efficiency. To evaluate the entire PI lecture, standardized tests are required, such as the Force Concept Inventory, which is an objective standardized test in mechanics (Hestenes, Wells \& Swackhamer, 1992). However, as there is no widely accepted standardized test in epidemiology, it is necessary to develop objective standard tests.

\section{Acknowledgments}


276

277

278

279

280

281

282

283

284

285

286

287

288

289

290

291

292

293

294

295

296

297

298

299

I am grateful to Yoko Oka for helping with the data management. I would like to thank

Editage (www.editage.jp) for English language editing.

\section{References}

Andriani A, Dewi I, Sagala PN. 2019. Development of blended learning media using the Mentimeter application to improve mathematics creative thinking skills. Journal of Physics: Conference Series 1188:12112. DOI: 10.1088/1742-6596/1188/1/012112.

Basioudis I. 2019. Icebreakers for business school students. In: Daniels K, Elliott C, Finley S, Chapman C, eds. Learning and Teaching in Higher Education. Cheltenham: Edward Elgar Publishing, 26-35.

Crouch CH. 1998. Peer instruction: An interactive approach for large lecture classes. Optics and Photonics News 9:37-41. DOI: 10.1364/opn.9.9.000037.

Crouch CH, Mazur E. 2001. Peer instruction: Ten years of experience and results. American Journal of Physics 69:970-977. DOI: 10.1119/1.1374249.

Dankner R, Gabbay U, Leibovici L, Sadeh M, Sadetzki S. 2018. Implementation of a competency-based medical education approach in public health and epidemiology training of medical students. Israel Journal of Health Policy Research 7:13. DOI: 10.1186/s13584017-0194-8.

Figueiredo APS, Figueiredo N. 2020. A quantitative analysis of the interaction among students in peer instruction classes. European Journal of Physics 41:015703. DOI: 10.1088/13616404/AB497B.

Fridsma DB. 2018. Health informatics: A required skill for 21st century clinicians. BMJ 362. DOI: $10.1136 / \mathrm{bmj} . \mathrm{k} 3043$.

Giuliodori MJ, Lujan HL, DiCarlo SE. 2006. Peer instruction enhanced student performance on 
300

301

302

303

304

305

306

307

308

309

310

311

312

qualitative problem-solving questions. Advances in Physiology Education 30:168-173. DOI: 10.1152/advan.00013.2006.

Goldmann E, Stark JH, Kapadia F, McQueen MB. 2018. Teaching epidemiology at the undergraduate level: Considerations and approaches. American Journal of Epidemiology 187:1143-1148. DOI: 10.1093/aje/kwy055.

Guzman LM, Pennell MW, Nikelski E, Srivastava DS. 2019. Successful integration of data science in undergraduate biostatistics courses using cognitive load theory. CBE Life Sciences Education 18:ar49. DOI: 10.1187/cbe.19-02-0041.

Haller H, Krauss S. 2002. Misinterpretations of significance: A problem students share with their teachers? Methods of Psychological Research Online 7:1-20.

Hestenes D, Wells M, Swackhamer G. 1992. Force concept inventory. The Physics Teacher 30:141-158. DOI: 10.1119/1.2343497.

Hilborn RC. 1997. [Review of the book Peer instruction: A user's manual, by E Mazur]. Physics Today 50:68-69. DOI: 10.1063/1.881735.

Huppenkothen D, Arendt A, Hogg DW, Ram K, VanderPlas JT, Rokem A. 2018. Hack weeks as a model for data science education and collaboration. Proceedings of the National Academy of Sciences of the United States of America 115:8872-8877. DOI: 10.1073/pnas.1717196115.

Kaneta M, Nitta H. 2009. Practice of peer instruction by use of clickers. Journal of the Physics Education Society of Japan 57:103-107. DOI: 10.20653/pesj.57.2_103.

Katyal R, Singh A, Joshi HS, Chandra S, Singh K. 2016. Enhancing student's learning by introducing various interactive teaching-learning methods in large group. International Journal of Biomedical and Advance Research 7: 363-368. DOI: 10.7439/ijbar.v7i8.3519.

Lasry N, Mazur E, Watkins J. 2008. Peer instruction: From Harvard to the two-year college. 
American Journal of Physics 76:1066-1069. DOI: 10.1119/1.2978182.

Macleod MR, Michie S, Roberts I, Dirnagl U, Chalmers I, Ioannidis JPA, Al-Shahi Salman R, Chan AW, Glasziou P. 2014. Biomedical research: Increasing value, reducing waste. The Lancet 383:101-104. DOI: 10.1016/S0140-6736(13)62329-6.

Martin F, Bolliger DU. 2018. Engagement matters: Student perceptions on the importance of engagement strategies in the online learning environment. Online Learning Journal 22:205222. DOI: $10.24059 /$ olj.v22i1.1092.

Moorhouse BL, Kohnke L. 2020. Using Mentimeter to elicit student responses in the EAP/ESP classroom. RELC Journal 51:198-204. DOI: 10.1177/0033688219890350.

Nitta H. 2010. Mathematical theory of peer-instruction dynamics. Physics Education Research 6:020105. DOI: 10.1103/PhysRevSTPER.6.020105.

Nitta H, Matsuura S, Kudo T. 2014. Implementation and analysis of peer-instruction in introductory physics lectures. Journal of Science Education in Japan 38:12-19. DOI: 10.14935/jssej.38.12.

Park SH, Do KH, Kim S, Park JH, Lim YS. 2019. What should medical students know about artificial intelligence in medicine? Journal of Educational Evaluation for Health Professions 16:18. DOI: 10.3352/jeehp.2019.16.18.

Pilzer S. 2001. Peer instruction in physics and mathematics. PRIMUS 11:185-192. DOI: $10.1080 / 10511970108965987$.

Relling AE, Giuliodori MJ. 2015. Effect of peer instruction on the likelihood for choosing the correct response to a physiology question. Advances in Physiology Education 39:167-171. DOI: $10.1152 /$ advan.00092.2014.

Rowley N, Green J. 2015. Just-in-time teaching and peer instruction in the flipped classroom to enhance student learning. Education in Practice 2:14-17. 
348 Sabale RV, Chowdary P. 2020. Flipped classroom - an innovative teaching model to train

349 undergraduate medical students in community medicine. Education for Health. 32:116-121.

350 DOI: $10.4103 /$ efh.EfH_116_18.

351 Sandercock P, Whiteley W. 2018. How to do high-quality clinical research 1: First steps.

352 International Journal of Stroke 13:121-128. DOI: 10.1177/1747493017750923.

353 Schmidt B. 2011. Teaching engineering dynamics by use of peer instruction supported by an

354

355

356

357

358

359

360

361

362

363

364

365

366

367

368

369

370

371 audience response system. European Journal of Engineering Education 36:413-423. DOI: 10.1080/03043797.2011.602185.

Shimizu I, Nakazawa H, Sato Y, Wolfhagen I, Könings KD. 2019. Does blended problem-based learning make Asian medical students active learners?: A prospective comparative study. BMC Medical Education 19:147. DOI: 10.1186/s12909-019-1575-1.

Sohn S, Lee Y-M, Jung J, Cha ES, Chun BC. 2019. The flipped classroom model for an undergraduate epidemiology course. Korean Journal of Medical Education 31:103-113. DOI: 10.3946/kjme.2019.122.

Takahashi H, Nitta H. 2009. A class of mechanics by adopting the peer instruction. Journal of the Physics Education Society of Japan 57:297-302. DOI: 10.20653/pesj.57.4_297.

Tauxe RV, Tormey MP, Mascola L, Hargrett-Bean NT, Blake PA. 1987. Salmonellosis outbreak on transatlantic flights; Foodborne illness on aircraft: 1947-1984. American Journal of Epidemiology 125:150-157. DOI: 10.1093/oxfordjournals.aje.a114498.

Tsuda T. 2003. Shimin no tameno ekigaku nyūmon: Igaku nyūsu kara kankyō saiban made. Tokyo: Ryokufü Shuppan.

University College London. 2018. Peer Instruction Transforms the Medical Science Classroom. [online] Available at: <https://www.ucl.ac.uk/teaching-learning/case-studies/2018/sep/peerinstruction-transforms-medical-science-classroom> [Accessed 12 May 2020]. 
372 Vázquez-García M. 2018. Collaborative-group testing improves learning and knowledge

373 retention of human physiology topics in second-year medical students. Advances in

374 Physiology Education 42:232-239. DOI: 10.1152/advan.00113.2017.

375 Zheng B, Zhang Y. 2020. Self-regulated learning: The effect on medical student learning

376 outcomes in a flipped classroom environment. BMC Medical Education 20:100. DOI:

$377 \quad 10.1186 /$ s12909-020-02023-6. 


\section{Table $\mathbf{1}$ (on next page)}

Table 1. Number of students and respondents in each ConcepTest 
1 Table 1. Number of students and respondents in each ConcepTest

\begin{tabular}{lcc}
\hline & & Number (percent) \\
\hline Number of students & & $121(100.0 \%)$ \\
Number of attendees & & $121(100.0 \%)$ \\
Female & & $34(28.1 \%)$ \\
Male & Before discussion & $87(71.9 \%)$ \\
Respondents of ConcepTest \#1 & After discussion & $120(99.2 \%)$ \\
& Before discussion & $101(83.5 \%)$ \\
Respondents of ConcepTest \#2 & After discussion & $115(95.0 \%)$ \\
Respondents of ConcepTest \#3 & Before discussion & $107(88.4 \%)$ \\
& After discussion & $116(95.9 \%)$ \\
Respondents of ConcepTest \#4 & Before discussion & $120(99.2 \%)$ \\
& After discussion & $107(88.4 \%)$ \\
& Before discussion & $101(83.5 \%)$ \\
& After discussion & $110(90.9 \%)$ \\
& & $106(87.6 \%)$ \\
\hline
\end{tabular}


Table 2 (on next page)

Table 2. Correct answer proportion and PI efficiency of ConcepTests \#1 \#5. 
1 Table 2. Correct answer proportion and PI efficiency of ConcepTests \#1 \#5.

\begin{tabular}{|c|c|c|c|c|c|}
\hline & $\# 1$ & $\# 2$ & $\# 3$ & $\# 4$ & $\# 5$ \\
\hline Number of respondents before discussion & 120 & 115 & 116 & 107 & 110 \\
\hline Number of respondents after discussion & 101 & 107 & 120 & 101 & 106 \\
\hline Correct answer proportion before discussion $\left(N_{b}\right)$ & 0.458 & 0.217 & 0.319 & 0.355 & 0.291 \\
\hline Correct answer proportion after discussion $\left(N_{a}\right)$ & 0.703 & 0.178 & 0.767 & 0.663 & 0.689 \\
\hline theoretical value of $N_{a}$ & 0.707 & 0.388 & 0.536 & 0.584 & 0.497 \\
\hline PI efficiency $(\eta)$ & 0.452 & -0.051 & 0.657 & 0.478 & 0.561 \\
\hline theoretical value of $\eta$ & 0.458 & 0.217 & 0.319 & 0.355 & 0.291 \\
\hline gap between measured and theoretical value & -0.007 & -0.268 & 0.338 & 0.123 & 0.270 \\
\hline
\end{tabular}


Figure 1

Figure 1. Scatter plot of correct answer proportion before and after discussion.

\section{\# 1- \# 5: Measured value of ConcepTest \# 1-\# 5}

Solid line: Theoretical value curve

Dotted line: Diagonal line, which means that there is no change in the correct answer proportion before and after the discussion.

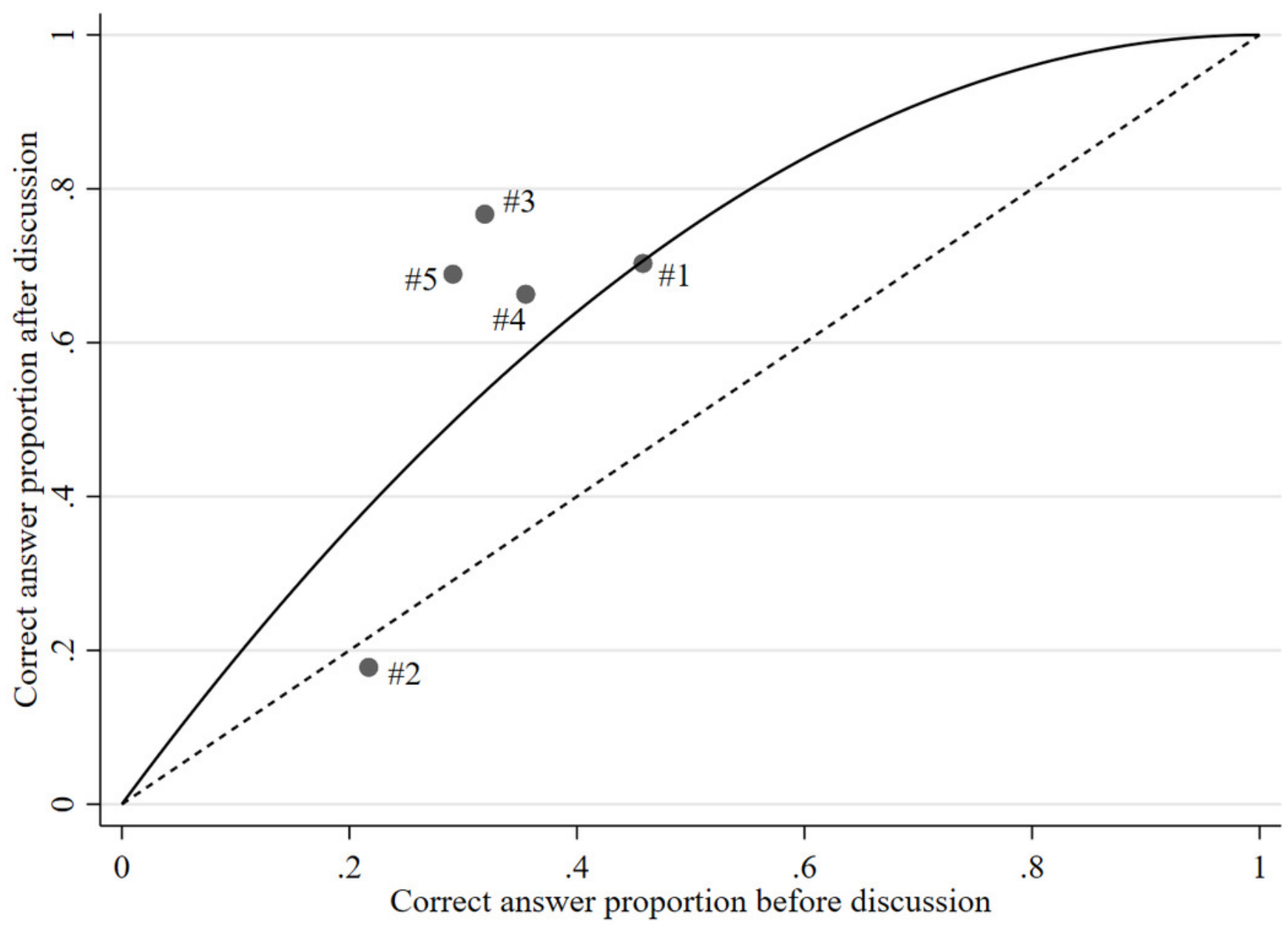


Figure 2

Figure 2. Scatter plot of correct answer proportion before discussion and PI efficiency.

\section{\# 1- \# 5: Measured value of ConcepTest \# 1-\# 5}

Solid line: Theoretical value curve

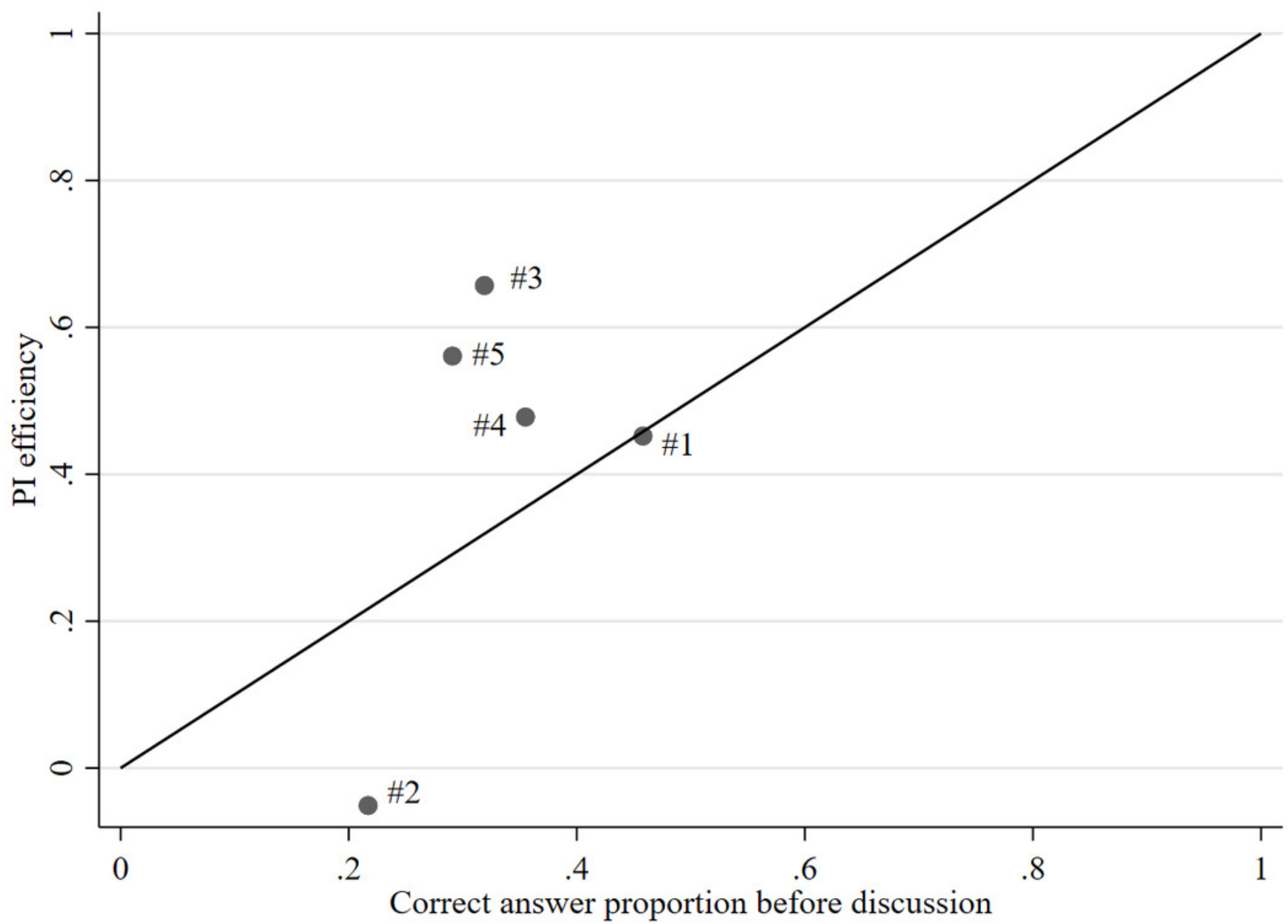

